\title{
Relação da Circunferência Escrotal e Parâmetros da Qualidade do Sêmen em Touros da Raça Nelore, PO
}

\author{
Antonio Emidio Dias Feliciano Silva1, Maria Marina Unanian¹, Célia Maria Torres Cordeiro, \\ Alfredo Ribeiro de Freitas ${ }^{2}$
}

RESUMO - Em 960 touros da raça Nelore, PO, de 11,4 a 135 meses de idade, pertencentes a fazendas localizadas nos Estados de São Paulo, Goiás e Pará, estudou-se a possível associação entre o tamanho da circunferência escrotal (CE) e os parâmetros da qualidade do sêmen, motilidade progressiva (MOT) e patologias espermáticas: defeitos maiores (DEFMAI), menores (DEFMEN) e totais (DEFTOT). Os touros foram divididos por faixas etárias em: menores que 18 , de 18 a 24, de 24 a 30, de 30 a 36 e maiores que 36 meses de idade. Este estudo foi realizado com a finalidade de obter tamanhos de CE que possam indicar o estatus funcional dos testículos, ou seja, a qualidade do sêmen, a serem utilizados para predizer o potencial reprodutivo dos animais destinados à seleção de reprodutores. Da correlação da CE com a MOT, por faixa etária, resultou uma associação $(\mathrm{R}=0,60 ; \mathrm{P}<0,0001)$ destes parâmetros nos touros até 18 meses de idade, em que CEs acima de $26 \mathrm{~cm}$ indicaram sêmen de alta MOT (60 a 80\%). As correlações entre CE e patologias espermáticas foram baixas e a maioria, negativa. Foi concluído, neste estudo, que nos touros jovens o tamanho da CE indica a qualidade do sêmen, portanto pode ser utilizado como um dos critérios na seleção de animais de alto potencial reprodutivo.

Palavras-chave: circunferência escrotal, motilidade, Nelore, patologias espermáticas

\section{Relationship of Scrotal Circumference and the Semen Quality Parameters in Nellore Purebred Bulls}

\begin{abstract}
In 960 Nellore purebred bulls, of 11.4 to 135 months of age, belonging to farms located in the São Paulo, Goiás and Para states, was studied the possible association among the size of the scrotal circumference (CE) and sperm quality parameters, progressive motility (MOT) and sperm pathologies: the major (DEFMAI), minor (DEFMIN) and total (DEFTOT) defects. The bulls were divided by age in groups: minor than 18 , from 18 to 24 , from 24 to 30 , from 30 to 36 and major than 36 months of age. This study was accomplished with the purpose of obtaining sizes of CE that may indicate the functional status of the testicles through the quality of the semen that can be used to predict the reproductive potential of the animals destined to the selection of bulls. Of the correlation of CE with MOT, by age group, resulted an association $(\mathrm{R}=0,60 ; \mathrm{P}<0.0001)$ of these parameters in the bulls up to 18 months of age, which CE above $26 \mathrm{~cm}$ indicated semen of high MOT (60 to 80\%). The correlation between CE and sperm pathologies was very low and negatives. It was concluded that in the young bulls the size of CE indicates the quality of the semen, therefore it can be used as a criteria for the selection of animals of high reproductive potential.
\end{abstract}

Key Words: motility, Nellore, scrotal circumference, sperm pathologies

\section{Introdução}

A eficiência ou capacidade reprodutiva ou fertilidade do touro é uma das mais importantes características do rebanho de corte, principalmente em se tratando de criações extensivas em que a reprodução constitui fator limitante à produção. A fertilidade do touro é avaliada pela taxa de prenhez/ano. Nos animais domésticos, esta taxa varia de 50 a $80 \%$ e depende, quase que exclusivamente, da capacidade funcional do esperma avaliado pela qualidade do sêmen produzido (Love \& Kenney, 1998).
De ponto de vista econômico, o sêmen de qualidade significa o rápido retorno do capital investido na criação de um reprodutor, principalmente quando este sêmen se destina à inseminação artificial, e o reprodutor apresenta outras características de interesse que determinam o seu intenso uso nos rebanhos.

Para avaliar a capacidade reprodutiva dos touros, têm sido propostos vários parâmetros envolvendo as medidas testiculares e a qualidade do sêmen (Silva et al., 1993). Entre os parâmetros propostos, o mais utilizado, principalmente em função da facilidade de

\footnotetext{
${ }^{1}$ Pesquisador, Embrapa Recursos Genéticos e Biotecnologia, PqEB, Final Av.W 5 Norte, Brasília/DF. E. mail: emidio@cenargen.embrapa.br; unanianm@aol.com

2 Pesquisador, Embrapa Pecuária Sudeste, São Carlos/SP.
} 
medição, é a circunferência (perímetro) escrotal, cujo tamanho foi relacionado à quantidade em volume da área ocupada pelo tecido testicular responsável pela produção de andrógenos (Lunstra et al., 1978) e espermatozóides (Aman, 1962).

A circunferência escrotal, além de fácil mensuração, apresenta herdabilidade de 0,57 e 0,44 , conforme encontrado por Cyrillo et al. (2001), e 0,41 por Ortiz Peña et al. (2001), e alta repetibilidade. Ainda, outro fator a ser considerado é a correlação positiva com o peso corporal em varias idades apresentada pela circunferência escrotal, sendo 0,18 à desmama (Eler et al., 1996) e 0,72 (Cyrillo et al., 2001) e 0,64 (Quirino \& Bergman, 1997) ao sobreano. Isto indica o potencial da circunferência escrotal como um dos fatores de seleção de touros.

Por outro lado, a capacidade reprodutiva de touros é avaliada, com precisão, pelo exame andrológico, que estabelece a concentração, motilidade e morfologia da população de espermatozóides ou ejaculado, e pelos testes funcionais constituídos da reação acrossômica induzida e integridade do acrossôma e cromatina, que permitem identificar a funcionalidade dos testículos para produção qualitativa de sêmen (Silva, 1998; Unanian, 2000).

Atualmente, as análises rotineiras consideram o sêmen de qualidade aquele que apresenta dois importantes atributos: motilidade progressiva e baixa taxa de espermatozóides anormais. Se da motilidade depende o alcance da célula feminina para fecundação, da presença da normalidade espermática depende, além da fecundação propriamente dita, a qualidade do embrião, em função do qual se evitam as perdas embrionárias no início da gestação (Silva et al., 1993). Um fator agravante envolvendo as anormalidades espermáticas é que a maioria é de natureza genética, portanto os reprodutores que as apresentam as transmitem para seus descendentes (Unanian, 1999).

Embora mostre o grau do potencial de fertilidade do macho, o exame andrológico e, em particular, o teste de funcionalidade, tem sido pouco utilizado, principalmente na seleção de zebuínos. Ainda, do ponto de vista seletivo, os parâmetros do sêmen apresentam baixa herdabilidade, sendo de 0,13 a 0,00 (Knights et al., 1984; Smith et al., 1989), e baixa correlação genética com a circunferência escrotal. As correlações encontradas por Knights et al. (1984) e Das \& Tomer (1995) foram de -0,26 e -0,005 para a concentração e de $-0,25$ e $-0,10$ para motilidade espermática, respectivamente.
Apesar de baixa a correlação entre a circunferência escrotal e os parâmetros do sêmen, tanto Smith et al. (1989) como Bertschinger et al. (1992), cujos resultados foram semelhantes aos de Knights et al. (1984) e Das \& Tomer (1995), ressaltaram a importância da circunferência escrotal para estimar a qualidade do sêmen. Bertschinger et al. (1992) observaram, em trabalho realizado com animais aos 18 meses de idade, uma relação curvilínea significante $(\mathrm{P}<0,001)$ entre a circunferência escrotal e a morfologia espermática, em que testículos com circunferências de $38 \pm 1 \mathrm{~cm}$ produziram sêmen com altas taxas $(80 \%)$ de espermatozóides normais.

A importância da circunferência escrotal na seleção de touros, tanto nos zebuínos como, principalmente, taurinos, tem sido abordada em vários estudos. No entanto, estes mesmos estudos, embora mencionem a importância do sêmen para avaliar a eficiência reprodutiva do macho, não se preocuparam estabelecer uma relação direta destes parâmetros. Em particular, em zebuínos é deficiente o conhecimento sobre a relação da circunferência escrotal, em várias idades, e a qualidade do sêmen, o que constitui o objetivo deste estudo. A relação entre o tamanho da circunferência escrotal e os parâmetros indicadores da qualidade do sêmen poderá constituir critério que favoreça a seleção de reprodutores.

\section{Material e Métodos}

O estudo foi realizado em 960 touros da raça Nelore, PO, provenientes de fazendas localizadas nos Estados de São Paulo, Goiás e Pará, de 11,4 aos 135 meses (cerca de um ano a 11 anos) de idade à coleta de sêmen, dividida por faixas etárias, a saber: menores que 18 meses, de 18 a 24 meses, de 24 a 30 meses, de 30 a 36 meses e maiores que 36 meses de idade, e criados a pasto (Brachiaria $\mathrm{sp}$ ) numa lotação de 0,8 a $1,0 \mathrm{UA} / \mathrm{ha}$.

Os animais foram analisados entre 1996 e 2000 , por ocasião da seleção para o início do período de cobertura, participação nas exposições e nos leilões, sendo realizadas duas coletas por touro.

Após a identificação, os touros foram submetidos ao exame clínico geral e dos genitais, em que se avaliou a circunferência escrotal (CE). Neste último exame, foram também avaliados a consistência testicular e o comportamento sexual - parâmetros que não fazem parte deste trabalho. 
Além da CE, foi realizado o exame andrológico, segundo Silva et al. (1993), coletando-se o sêmen por meio de eletroejaculador, e imediatamente após analisados o volume do ejaculado $(\mathrm{mL})$, a motilidade progressiva (MOT, \%) e o vigor (escore de 1 a 5) dos espermatozóides. Em cada ejaculado, foram também avaliadas a concentração (espermatozóides x 106/mL) e as características morfológicas dos espermatozóides (\%), sendo observada a presença de: defeitos maiores (DEFMAI), menores (DEFMEN) e total de defeitos ou patologias espermáticas (DEFTOT). Para análise das patologias espermáticas, foram contados 200 espermatozóides.

Dos parâmetros estudados foram obtidas estatísticas descritivas (médias pontuais).

A associação dos parâmetros do sêmen MOT, DEFMAI, DEFMEN e DEFTOT com a CE foi apresentada por meio de gráficos e quantificada pelos seus respectivos coeficientes de correlação (correlação de Pearson), ajustados para a idade à coleta do sêmen dentro de cada faixa etária, usando o Proc CORR do SAS (SAS, 1995).

A CE em função da idade à coleta do sêmen foi analisada por regressão não-linear, utilizando-se o modelo exponencial negativo:

$$
\mathrm{CE}_{\mathrm{i}}=\mathrm{B}_{0}\left(1-\exp \mathrm{B}_{1}^{\text {idade }}\right)+\varepsilon_{\text {, }}
$$

em que: o parâmetro $B_{0}$ pode ser interpretado como o valor assintótico (médio) da CE dos touros destes rebanhos. A taxa de crescimento instantâneo (CT) da $\mathrm{CE}$, expressa $\mathrm{em} \mathrm{cm} / \mathrm{dia}$, foi calculada a partir do modelo acima descrito.

\section{Resultados e Discussão}

Constam na Tabela 1 as médias (médias pontuais) observadas para os parâmetros: circunferência escrotal, motilidade espermática progressiva e patologias espermáticas dos touros nas idades de 18 até 42 meses. Acima de 42 meses, embora tenham sido observados 960 touros, não foi possível estabelecer as médias pontuais dos parâmetros estudados, em razão do pequeno número de animais.

As médias da CE obtidas aos 18 meses de idade foram maiores que as observadas por Ortiz Peña et al. (2000) e Unanian et al. (2000), de 25,71 e 23,68 cm em machos da raça Nelore, respectivamente. Mesmo aos 42 meses, a média da CE foi superior à encontrada por Silva et al. (1991 a), 31,60 cm, nesta mesma idade. A diferença entre os valores encontrados nos touros da raça Nelore deste estudo e os descritos na literatura deve-se, provavelmente, à origem dos touros, que, na maioria, pertenciam a rebanhos que já adotam a CE como fator de seleção de reprodutores.

$\mathrm{O}$ tamanho testicular mensurado pela $\mathrm{CE}$ variou com a idade à coleta do sêmen $\left(\mathrm{R}^{2}=0,65\right)$ e apresentou crescimento diferenciado em função desta (Figura 1). O CT ocorreu de forma acentuada na faixa etária de 11,4 até 18 meses de idade, sendo aos 11,4 e 18 meses de 0,04170 e $0,02578 \mathrm{~cm} /$ dia, respectivamente. Este valor de CT foi maior que os observados na mesma idade por Ortiz Peña et al. (2000) de 0,03833 cm/dia, em Nelore, e Lunstra et al. (1978) de $0,032 \mathrm{~cm} / \mathrm{dia}$, em Bos taurus. Dos 18 aos 24 meses, o CT diminuiu para $0,02142 \mathrm{~cm} /$ dia, sendo de $0,01419 \mathrm{~cm} /$ dia de 24

Tabela 1 - Médias pontuais ( \pm DP) da circunferência escrotal (CE), motilidade progressiva e patologias espermáticas dos touros da raça Nelore, $\mathrm{PO}$

Table 1 - Means ( $\pm S D$ ) of scrotal circumference (SC), progressive motility and sperm pathologies parameters of Nellore purebred bulls

\begin{tabular}{lrlccrr}
\hline $\begin{array}{l}\text { Idade (meses) } \\
\text { Age (months) }\end{array}$ & $\mathrm{N}$ & $\begin{array}{l}\mathrm{CE}(\mathrm{cm}) \\
S C(\mathrm{~cm})\end{array}$ & $\begin{array}{c}\text { Motilidade progressiva (\%) } \\
\text { Progressive motility (\%) }\end{array}$ & DEFMAI(\%) & DEFMEN(\%) & DEFTOT(\%) \\
\hline 18 & 32 & $27,22 \pm 4,84$ & $41,5 \pm 29,4$ & $18,5 \pm 12,4$ & $5,8 \pm 9,4$ & $24,3 \pm 17,3$ \\
24 & 186 & $31,90 \pm 2,86$ & $66,0 \pm 13,5$ & $9,8 \pm 12,3$ & $3,6 \pm 5,8$ & $13,4 \pm 13,7$ \\
30 & 118 & $33,17 \pm 2,03$ & $67,3 \pm 12,3$ & $6,5 \pm 3,6$ & $4,6 \pm 5,2$ & $11,1 \pm 6,8$ \\
36 & 21 & $33,67 \pm 2,63$ & $60,7 \pm 17,3$ & $8,8 \pm 13,0$ & $5,5 \pm 7,5$ & $14,3 \pm 16,2$ \\
42 & 9 & $36,33 \pm 2,29$ & $72,8 \pm 7,1$ & $6,8 \pm 3,6$ & $3,3 \pm 3,2$ & $10,1 \pm 5,7$ \\
$>48$ & 25 & $37,36 \pm 2,90$ & $72,8 \pm 10,3$ & $9,5 \pm 8,9$ & $3,1 \pm 3,5$ & $12,6 \pm 11,5$ \\
\hline
\end{tabular}

$\mathrm{N}=$ número de touros.

Patologias espermáticas: DEFMAI = defeitos maiores.

DEFMEN = defeitos menores.

$N=$ number of bulls.

DEFTOT $=$ defeitos totais

Sperm pathologies: $D E F M A I=$ major defects

$D E F M E N=$ minor defects

$D E F T O T=$ total defects.

R. Bras. Zootec., v.31, n.3, p.1157-1165, 2002 


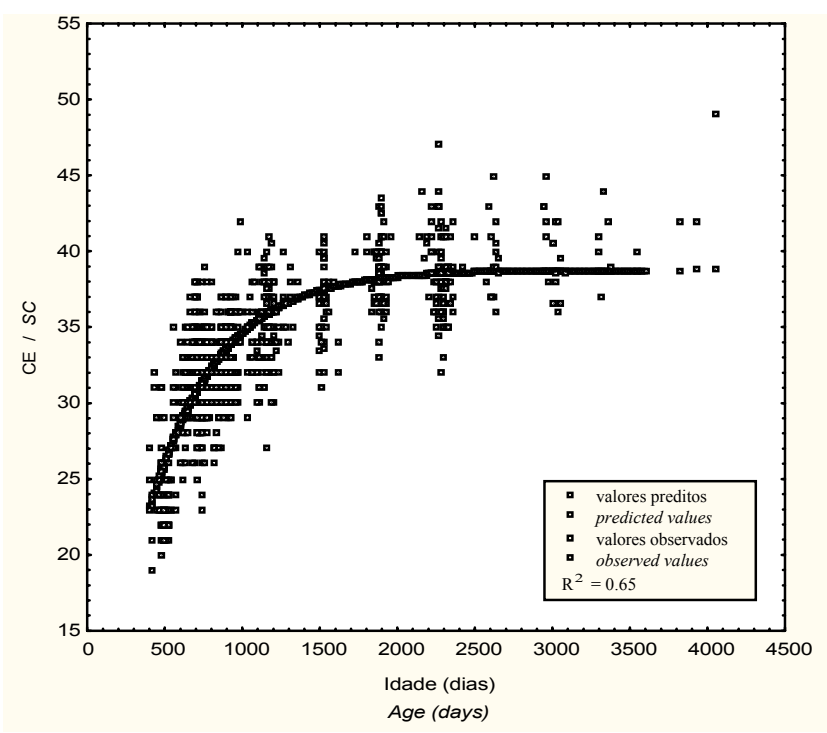

Figura 1 - Circunferência escrotal (CE) em função da idade à coleta de sêmen em touros da raça Nelore, PO.

Figure 1 - Scrotal circumference (SC) by age of sperm sampling in Nellore purebred bulls.

até 30 meses e $0,00939 \mathrm{~cm} /$ dia de 30 até 36 meses de idade, mostrando que nos rebanhos estudados os testículos param de crescer entre dois e três anos de idade. Nesta faixa etária há indicação de que o parênquima testicular e epitélio epididimário já estão definidos, havendo apenas indivíduos dentro dos rebanhos com maturidade fisiológica tardia (Barth \& Oko, 1989), fato que, provavelmente, influenciou os CTs encontrados nos touros da raça Nelore dos 24 a 36 meses de idade. Portanto, o CT, principalmente observado entre 30 e 36 meses, ocorreu devido ao aumento do tecido adiposo, e não do tecido testicular propriamente dito, ou seja, endócrino constituído das células de Leydig e reprodutivo dos túbulos seminíferos (Coulter \& Foote, 1979; Swerdloff \& Wang, 1996). Nas demais faixas etárias, o CT variou de 0,006 a $0,0001 \mathrm{~cm} /$ dia (96 a 135 meses), ou seja, próximo ao zero (linha continua da Figura 1).

A motilidade progressiva observada no sêmen dos touros da raça Nelore (Tabela 1) aumentou com a idade, sendo semelhante à descrita por Silva et al. (1991 b). Em todas as faixas etárias, foi verificada alta variação individual, em que os touros apresentaram MOT de 5 a $95 \%$ (Figura 2). A maior variação da MOT ocorreu nos touros jovens até 18 meses (5 a $80 \%$ ), em um intervalo de CE de 21 a $26 \mathrm{~cm}$. Esta

R. Bras. Zootec., v.31, n.3, p.1157-1165, 2002 ampla variação da MOT deve-se, provavelmente, ao desenvolvimento destes animais que deveriam estar na fase puberal ou próximos desta e, portanto, apresentando epitélio seminífero, todavia, em formação (Lunstra et al., 1978). Nas demais faixas etárias, na maioria dos animais $(90 \%)$, principalmente acima de 24 meses de idade, a MOT continuou apresentando alta variação, porém com amplitude menor, de 40 a $80 \%$. A MOT, nesta amplitude, foi distribuída, conforme a faixa etária, entre os tamanhos de CE de 27 e 36 $\mathrm{cm}$ nos touros de 18 a 30 meses, de 31 a $36 \mathrm{~cm}$ nos de 30 a 36 meses, e de 32 a $40 \mathrm{~cm}$ nos touros acima de 36 meses de idade. Estes resultados mostram a existência de alta variação individual na qualidade do sêmen avaliada pela MOT, em que os touros da raça Nelore dentro da mesma idade e mesmo tamanho testicular apresentaram taxas diferentes de MOT. Esta variação mostrou que os testículos com tamanhos iguais podem produzir sêmen tanto de baixa como alta MOT. Portanto, esta produção de sêmen deve-se à funcionalidade testicular do animal, e não somente ao tamanho da CE. Esta variação da MOT poderia ser atribuída a fatores genéticos, fisiológicos, como proteínas e fatores de crescimento que interferem no desenvolvimento e funcionalidade dos testículos (Lin, 1996), ou externos, que podem comprometer a normalidade na qualidade do sêmen temporariamente ou não, considerando que a espermatogênese é um processo contínuo (Barth \& Oko, 1989; Vogler et al., 1993; Thundathil et al., 2001). Ainda, poderia ser uma característica racial destes rebanhos, uma vez que isto não foi observado, com a mesma amplitude, nos animais Bos taurus (Smith et al., 1989).

Por outro lado, a falta de associação entre MOT e CE nos touros adultos e a alta variação individual destes parâmetros poderia ser o resultado da seleção, cujos critérios, até recentemente, não incluíam as características reprodutivas (Silva et al., 1993). Estes resultados foram semelhantes aos de Smith et al. (1989), os quais observaram que a correlação entre a MOT e CE diminui com a idade, tornando-se baixa nos reprodutores adultos. Outra hipótese para esta baixa correlação MOT e CE poderia ser a consangüinidade dos rebanhos (Smith et al., 1989).

A alta variação da MOT, nos touros adultos (acima dos 24 meses de idade), em função da $\mathrm{CE}$ e idade à coleta do sêmen, foi semelhante à observada por Das \& Tomer (1995), sendo atribuída, por estes autores, à variabilidade genética e, ainda, ao sistema de criação, que pode influenciar a produção e qualidade 


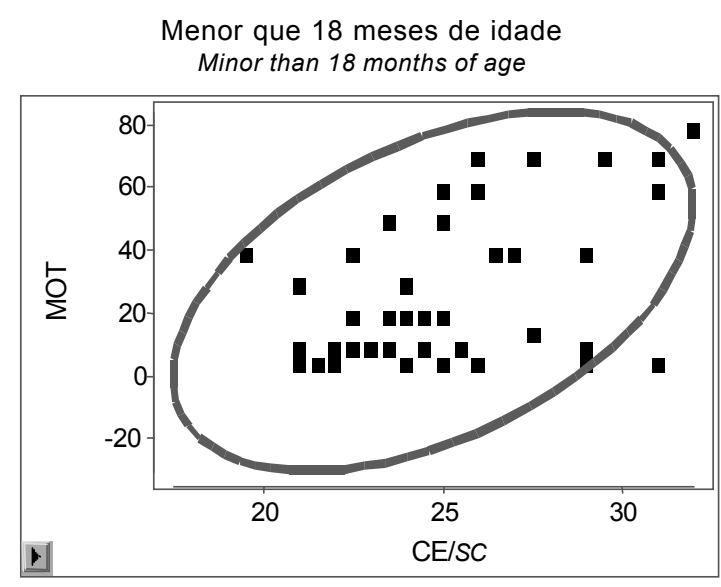

18 a 24 meses de idade 18 to 24 months of age

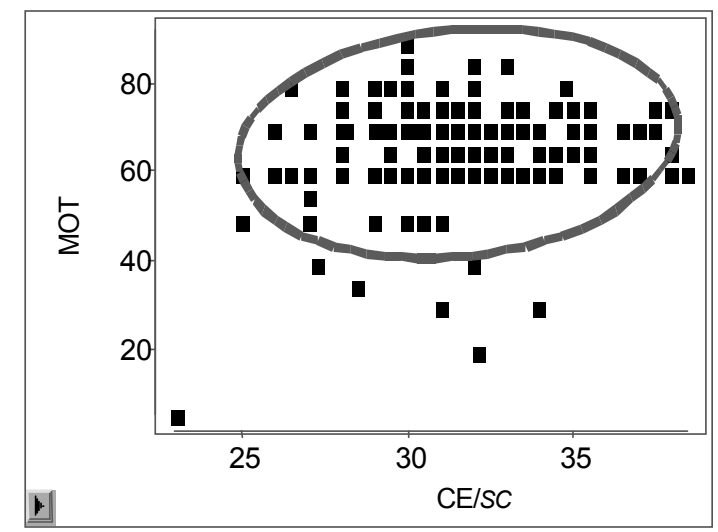

30 a 36 meses de idade 30 to 36 months of age

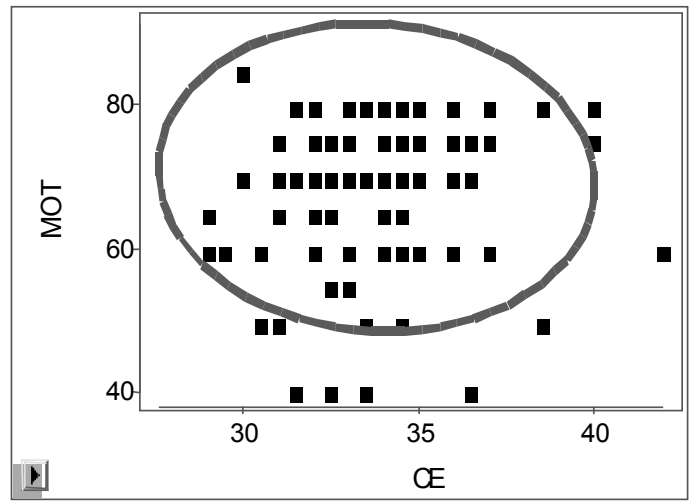

maior que 36 meses de idade major than 36 months of age

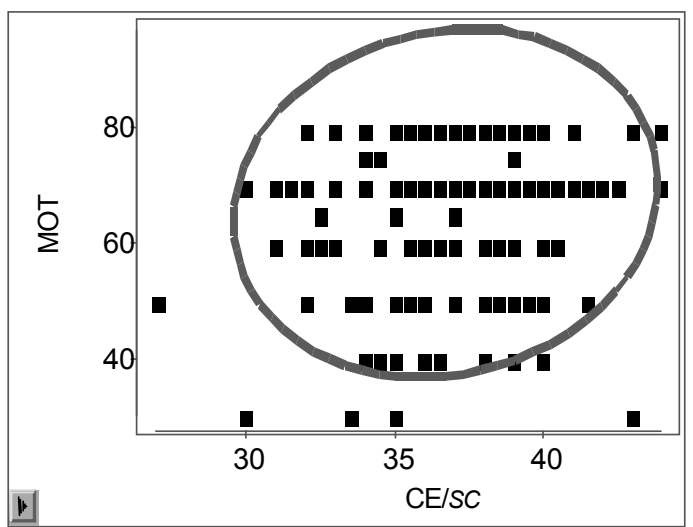

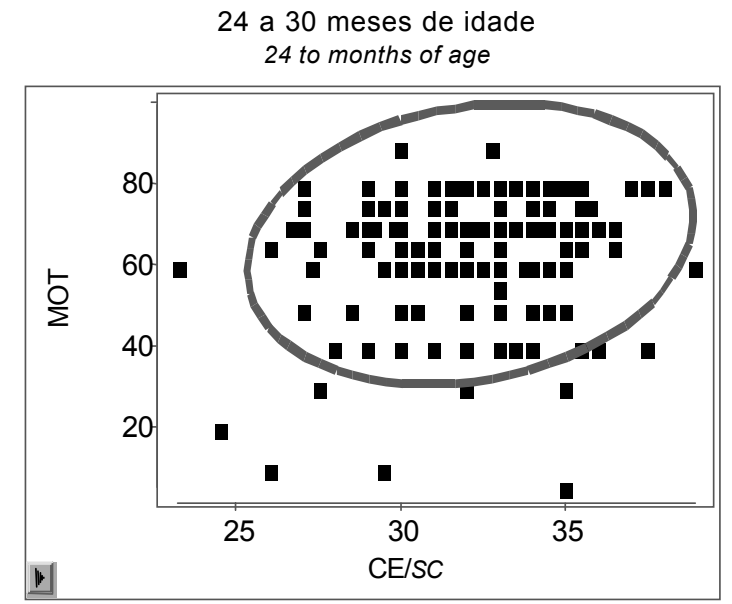

Figura 2 - Elipse com 95\% de confiança da motilidade progressiva (MOT, \%) do sêmen e circunferência escrotal $(\mathrm{CE}, \mathrm{cm})$, por faixa etária, em touros da raça Nelore, PO.

Figure 2 - Ellipse with 95\% confidence of sperm progressive motility (MOT, \%) and scrotal circumference $(\mathrm{SC}, \mathrm{cm})$, by age interval, in Nellore purebred bulls. 
do sêmen, conforme observado também por Silva et al. (1993).

Independentemente da idade, a correlação da MOT com a CE foi de média intensidade $(\mathrm{R}=0,35758 ; \mathrm{P}<0,0001)$. No entanto, as correlações da MOT com a CE, por faixa etária, mostram que apenas até os 18 meses de idade (Tabela 2) houve influência do tamanho da CE sobre a MOT, nas demais faixas etárias esta correlação foi baixa e não-significativa. Nos animais com idades inferiores a 18 meses, touros jovens em crescimento, a correlação MOT $\mathrm{x}$ $\mathrm{CE}$ foi alta e significativa $(\mathrm{R}=0,60 ; \mathrm{P}<0,0001)$, sendo constatado que, na maioria destes touros $(87 \%)$, a taxa da MOT foi baixa (5 a 20\%), quando os testículos tinham CE de 21 a $26 \mathrm{~cm}$, e alta (60 a 80\%), quando os testículos apresentaram CE acima de $26 \mathrm{~cm}$. Isto indica que, nesta faixa etária, o sêmen com altas taxas de MOT, próximas ao padrão de referência de sêmen considerado de boa qualidade e dentro dos limites fisiológicos necessários à fecundação (Silva et al., 1993), é proveniente de testículos maiores.

A relação da CE acima de $26 \mathrm{~cm}$ e idade até 18 meses sugere que os testículos nestas condições podem se constituir em um fator a ser utilizado na seleção de reprodutores, pois é alta a probabilidade destes reprodutores apresentarem sêmen de qualidade em função deste tamanho testicular. Esta observação poderá complementar os critérios adotados à escolha de animais até de 18 meses de idade, potenciais reprodutores, como já ocorre em algumas das propriedades selecionadoras (Silva, 1997).

A correlação encontrada entre a MOT e CE nos animais até 18 meses de idade foi maior que a descrita por Moura et al. (2000), em touros da raça Nelore ( $\mathrm{R}=0,39 ; \mathrm{P}<0,05)$ e Das \& Tomer (1995), em touros mestiços $(R=0,33 ; P<0,01)$. Nos reprodutores acima dos 18 meses de idade, a correlação entre a MOT e CE foi semelhante à descrita por Smith et al. (1989) em touros das raças Angus, Red Angus e Hereford $(\mathrm{R}=0,13)$.

As médias pontuais das patologias espermáticas, defeitos maiores (DEFMAI) menores (DEFMEN) e totais (DEFTOT), dos touros jovens e adultos estão apresentadas na Tabela 1, sendo as taxas observadas menores das descritas por Silva et al. (1991 b).

Nos touros jovens, até 18 meses de idade, ocorreu a maior taxa de patologias espermáticas, respectivamente dos DEFMAI e DEFTOT, sendo esta taxa distribuída entre os tamanhos de CE de 21 a $31 \mathrm{~cm}$ (Figura 3). Uma das causas desta alta taxa foi o número de gotas citoplasmáticas proximais encontradas no sêmen destes touros (12,72\%), cujo aparecimento pode ser considerado normal, em função do estado de maturação do epitélio epididimário e dos espermatozóides (Barth \& Oko, 1989; Silva et al., 1993). Como a maior parte destas patologias

Tabela 2 - Coeficientes de correlação parcial (idade) entre motilidade progressiva e patologias espermáticas com a circunferência escrotal, em touros da raça Nelore, PO

Table 2 - Partial correlation coefficients between progressive motility and sperm pathologies with scrotal circumference in Nellore purebred bulls

\begin{tabular}{|c|c|c|c|c|c|}
\hline \multirow[b]{2}{*}{$\begin{array}{l}\text { Idade (meses) } \\
\text { Age (months) }\end{array}$} & \multirow[b]{2}{*}{$\mathrm{N}$} & \multicolumn{4}{|c|}{$\begin{array}{l}\text { Parâmetros do sêmen } \\
\text { Sperm parameters }\end{array}$} \\
\hline & & MOT (\%) & DEFMAI(\%) & DEFMEN (\%) & DEFTOT $(\%)$ \\
\hline$<18$ & 125 & $0,60(0,0001)$ & $-0,18(0,0475)$ & $-0,04(0,6799)$ & $-0,18(0,0487)$ \\
\hline 18 a 24 & 318 & $0,11(0,0467)$ & $-0,07(0,2397)$ & $0,00(0,9394)$ & $-0,05(0,3293)$ \\
\hline 24 a 30 & 211 & $0,17(0,0128)$ & $-0,17(0,0142)$ & $-0,01(0,9156)$ & $-0,15(0,0291)$ \\
\hline 30 a 36 & 127 & $0,05(0,5458)$ & $0,01(0,8816)$ & $0,11(0,2296)$ & $0,07(0,4106)$ \\
\hline$>36$ & 128 & $0,15(0,0889)$ & $-0,11(0,2226)$ & $0,07(0,4498)$ & $-0,05(0,5761)$ \\
\hline
\end{tabular}

Valores entre parênteses mostram o nível de significância.

$\mathrm{N}=$ número de touros.

MOT = motilidade progressiva do semên .

Patologias espermáticas: DEFMAI = defeitos maiores.

DEFMEN $=$ defeitos menores.

DEFTOT $=$ defeitos totais.

Values within parenthesis show the significant level.

$N=$ number of bulls.

$M O T=$ progressive sperm motility.

Sperm pathologies: $D E F M A I=$ major defects $D E F M I N=$ minor defects $D E F T O T=$ total defects

R. Bras. Zootec., v.31, n.3, p.1157-1165, 2002 
Menor que 18 meses de idade

Minor than 18 months of age
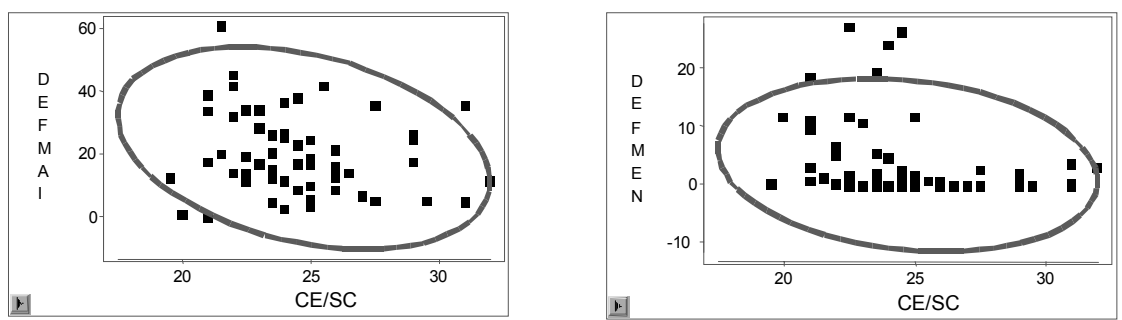

18 a 24 meses de idade

18 to 24 months of age
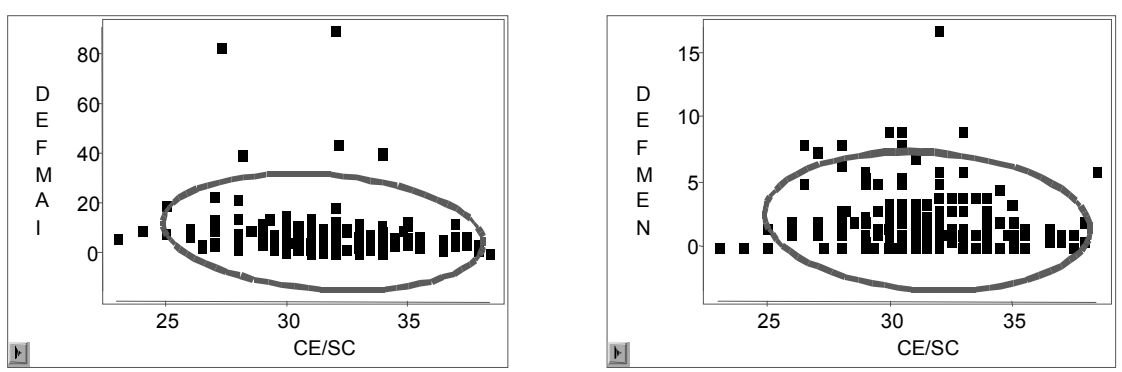

24 a 30 meses de idade 24 a 30 months of age
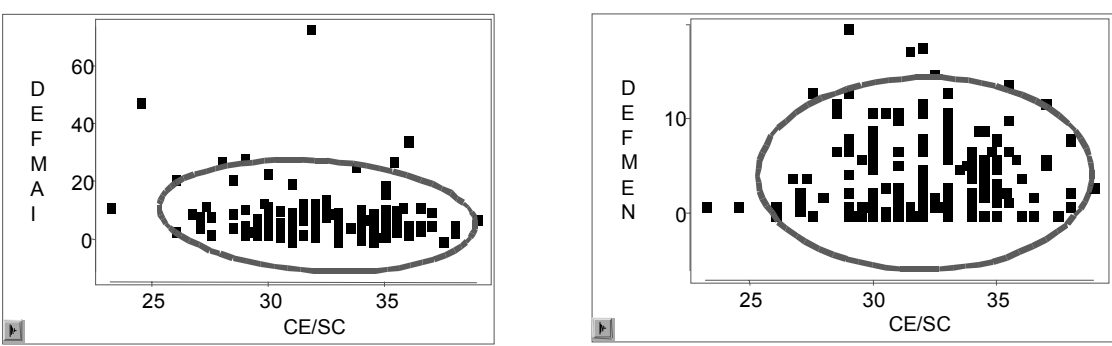

30 a 36 meses de idade 30 a 36 months of age
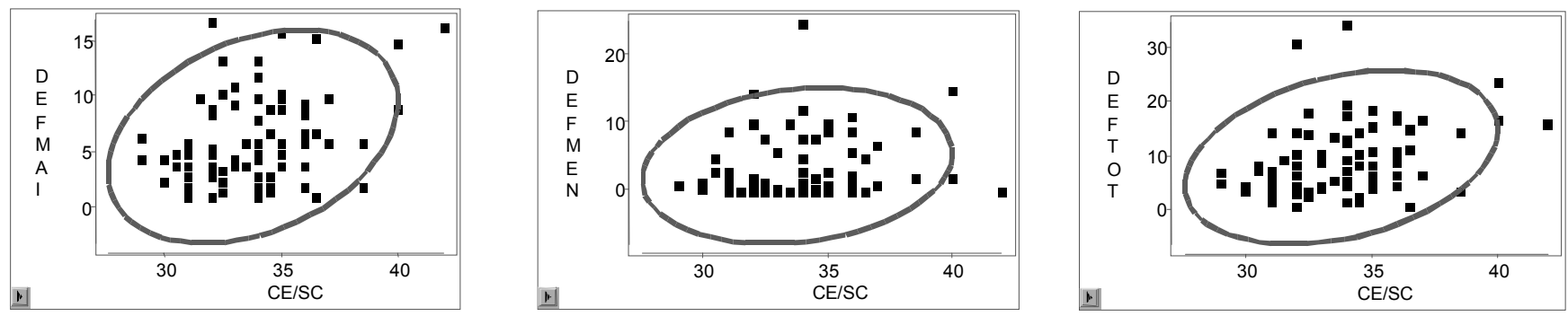

maior que 36 meses de idade major than 36 months of age

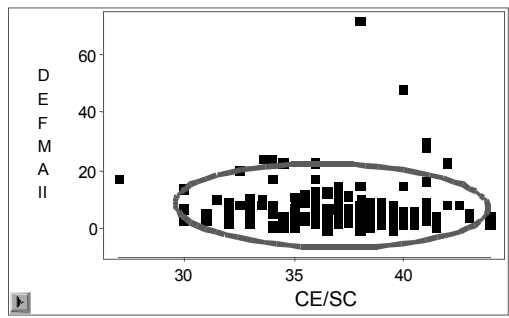

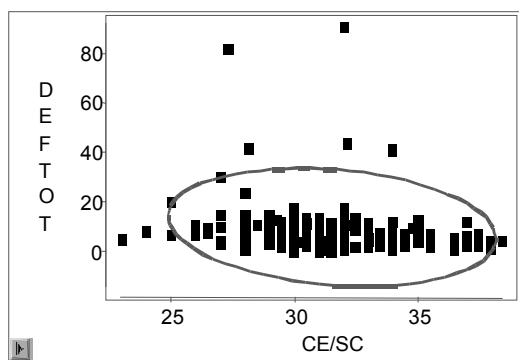
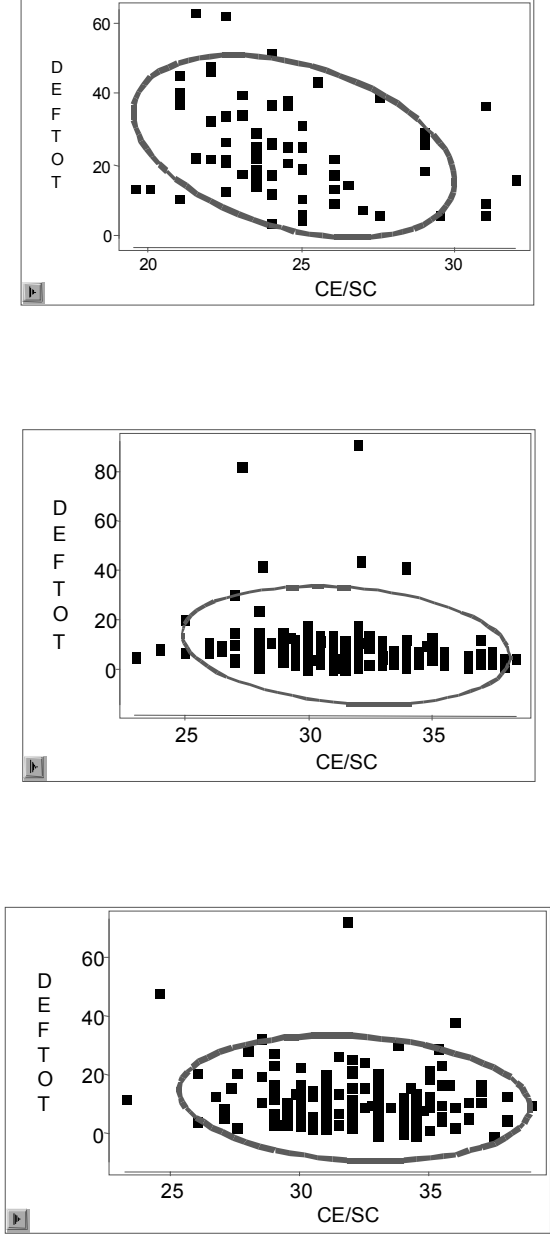

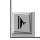

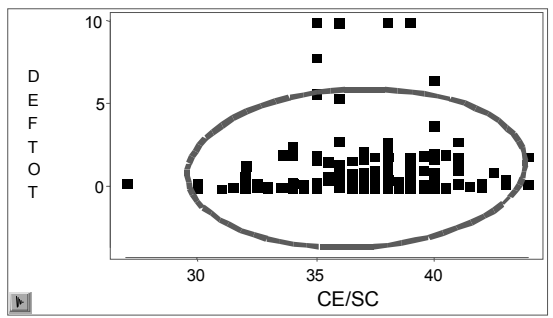

Figura 3 - Elipse com 95\% de confiança das patologias espermáticas: defeitos maiores (DEFMAI, \%), menores (DEFMEN, $\%$ ) e totais (DEFTOT, \%) e circunferência escrotal (CE, cm), por faixa etária, em touros da raça Nelore, PO.

Figure 3 - Ellipse with 95\% confidence of sperm pathologies: major (DEFMAl, \%), minor (DEFMEN, \%) and total (DEFTOT, \%) defects and scrotal circumference (SC, $\mathrm{cm})$, by age interval, in Nellore purebred bulls.

R. Bras. Zootec., v.31, n.3, p.1157-1165, 2002 
espermáticas tem sua origem nos testículos cujo tecido epitelial em animais jovens até 18 meses de idade encontram-se, todavia, em desenvolvimento e imaturos, esta condição pode ocasionar alterações na espermatogênese, que pode levar ao aparecimento de maior número de patologias espermáticas (Söderquist et al., 1991).

As taxas de patologias espermáticas diminuíram com o aumento da idade, como também observado por Troconiz et al. (1991) e Palasz et al. (1994), apresentando, na maioria dos touros adultos, porcentagens iguais ou inferiores a $20 \%$, ou seja, dentro da normalidade morfológica do sêmen para uso na monta natural ou artificial (Silva et al., 1993). Relacionando estas taxas de anomalias espermáticas iguais ou inferiores a $20 \%$ à idade e CE, foi constatado que nos touros até 18 meses estas taxas apareceram em CEs de 21 a $26 \mathrm{~cm}$, nos de 18 a 30 meses em CEs de 26 a $37 \mathrm{~cm}$, e nas demais idades em CEs acima de $30 \mathrm{~cm}$.

Em todas as faixas etárias estudadas, as correlações entre as patologias espermáticas e a CE foram muito baixas e a maioria, negativa (Tabela 2). Os touros jovens, até 18 meses de idade, foram os que apresentaram a mais alta correlação de patologias espermáticas com a $\mathrm{CE}(\mathrm{R}=-0,18 ; \mathrm{P}<0,0475)$, sendo esta maior da observada por Smith et al. (1989) em animais das raças Hereford, Angus e Red Angus, na mesma faixa etária.

Embora as associações entre as patologias espermáticas e a CE tenham sido baixas, vários touros com CEs maiores produziram sêmen com taxas menores de DEFMAI e DEFTOT, tendência também observada por Palasz et al. (1994).

Em nenhuma das faixas etárias foi encontrado um tamanho de CE que possa indicar o estatus de normalidade ou anormalidade do sêmen, como observado e indicado por Bertschinger et al. (1992).

\section{Conclusões}

O tamanho da circunferência escrotal em touros jovens até 18 meses de idade, um dos importantes critérios para seleção de reprodutores, pode indicar a qualidade do sêmen representada pela motilidade progressiva dos espermatozóides.

O tamanho da circunferência escrotal, independentemente da idade, não influenciou a taxa de patologias espermáticas.

\section{Literatura Citada}

AMAN, R.P. Reproductive capacity of dairy bulls. IV. Spermatogenesis and testicular germ cell degeneration. American Journal of Anatomy, v.110, p.69-78, 1962.

BARTH, A.D.; OKO, R.J. Abnormal morphology of bovine spermatozoa. Ames: Iowa State University Press, 1989. 348p.

BERTSCHINGER, H.J.; EHRET, W.J.; WOOD, R. et al. Beef bull performance, scrotal circumference and semen quality. In: INTERNATIONAL CONGRESS ON ANIMAL REPRODUCTION, 12, 1992, The Hague. Proceedings... The Hague: University of Waageningen, 1992. p.1525-1527.

COULTER, G.H.; FOOTE, R.H. Bovine testicular measurements as indicators of reproductive performance and their relationship to productive traits in cattle: a review. Theriogenology, v.11, n.4, p.297-311, 1979.

CYRILLO, J.N.S.G.; RAZOOK, A.G.; FIGUEIREDO, L.A. et al. Estimativa de tendências e parâmetros genéticos do peso padronizado aos 378 dias de idade, medidas corporais e perímetro escrotal de machos Nelore de Sertãozinho, SP. Revista Brasileira de Zootecnia, v.30, n.1, p.56-65, 2001.

DAS, S.K.; TOMER, O.S. Studies on testicular biometry and semen quality in cattle and buffalo. Indian Journal of Dairy Science, v.48, n.1, p.78-81, 1995.

ELER, J.P.; FERRAZ, J.B.; SILVA, P.R. Estimação simultânea de parâmetros genéticos para características de importância econômica na raça Nelore, com a utilização de modelos animais. In: REUNIÃO ANUAL DA SOCIEDADE BRASILEIRA DE ZOOTECNIA, 33., 1996, Fortaleza. Anais... Viçosa, MG: Sociedade Brasileira de Zootecnia, 1996. p.99-101.

KNIGHTS, S.A.; BAKER, R.L.; GIANOLA, D. et al. Estimates of heritabilities and of genetic and phenotypic correlations among growth and reproductive traits in yearling Angus bulls. Journal of Animal Science, v.58, n.4, p.887-893, 1984.

LIN, T. Insulin-like growth factor-I regulation of the Leydig Cell. In: PAYNE, A.H.; HARDY, M.P.; RUSSELL, L.D. (Eds.) The Leydig cell. Vienna: Cache River, 1996. p.476-491.

LOVE, C.C.; KENNEY, R.M. The relationship of increased susceptibility of sperm DNA to denaturation and fertility in the stallion. Theriogenology, v.50, p.955-972, 1998.

LUNSTRA, D.D.; FORD, J.J.; ECHTERNKAMP, S.E. Puberty in beef bulls: hormone concentrations, growth, testicular development, sperm production and sexual aggressiveness in bulls of different breeds. Journal of Animal Science, v.46, n.4, p.1054-1062, 1978.

MOURA, A.A.A.; RODRIGUES, G.C.; GARCIA, F.C. Desenvolvimento testicular, concentrações séricas de testosterona e produção espermática em touros Nelore. In: REUNIÃO ANUAL DA SOCIEDADE BRASILEIRA DE ZOOTECNIA, 37., 2000, Viçosa. Anais... Viçosa: Sociedade Brasileira de Zootecnia, 2000. p.1-3.

ORTIZ PEÑA, C.D.; QUEIROZ, S.A.; FRIES, L.A. Estimação de fatores de correção do perímetro escrotal para idade e peso corporal em touros jovens da raça Nelore. Revista Brasileira de Zootecnia, v.30, n.1, p.93-100, 2001.

QUIRINO, C.R.; BERGMANN, J.A. Herdabilidade do perímetro escrotal ajustado e não ajustado para peso corporal usando modelo animal uni e bivariado. In: REUNIÃO ANUAL DA SOCIEDADE BRASILEIRA DE ZOOTECNIA, 34., 1997, Juiz de Fora. Anais... Viçosa: Sociedade Brasileira de Zootecnia, 1997. p.127-129.

PALASZ, A.T.; CATES, W.F.; BARTH, A.D. et al. The relationship between scrotal circumference and quantitative

R. Bras. Zootec., v.31, n.3, p.1157-1165, 2002 
testicular traits in yearling beef bulls. Theriogenology, v.42, p.715-726, 1994.

SAS INSTITUTE. Sas user's guide: statistics. Versão 6.0, Cary: 1995. 956p.

SILVA, A.E.D.F. Identificação da puberdade através do sêmen em machos da raça Nelore. In: SIMPÓSIO DO NELORE DO SÉCULO XXI, 4., 1997, Uberaba. Anais... Uberaba: Associação Brasileira dos Criadores de Zebu, 1997. p.63-71.

SILVA, A.E.D.F. Reação acrossômica induzida: método indicador de fertilidade de touros. Brasília: EMBRAPA Recursos Genéticos e Biotecnologia, 1998. 38p. (EMBRAPA Recursos Genéticos e Biotecnologia. Documentos, 35).

SILVA, A.E.D.F.; DODE, M.A.N.; UNANIAN, M.M. Capacidade reprodutiva do touro de corte: funções, anormalidades e outros fatores que a influenciam. Campo Grande: EMBRAPA-CNPGC, 1993. 128p. (EMBRAPA-CNPGC. Documentos, 51).

SILVA, A.E.D.F.; DODE, M.A.N.; PORTO, J.A. et al. Estacionalidade na atividade sexual de machos bovinos Nelore e mestiços Fleckvieh e Chianina x Nelore: características biométricas testiculares. Pesquisa Agropecuária Brasileira, v.26, n.10, p.1745-1750, 1991a.

SILVA, A.E.D.F.; DODE, M.A.N.; PORTO, J.A. et al. Estacionalidade na atividade sexual de machos bovinos Nelore e mestiços Fleckvieh e Chianina x Nelore: características espermáticas. Pesquisa Agropecuária Brasileira, v.26, n.10, p1751-1760, 1991b.

SMITH, B.A.; BRINKS, T.S.; RICHARDSON, G.V. Estimation of genetic parameters among breeding soundness examination components and growth traits in yearling bulls. Journal of Animal Science, v.67, n.4, p.2892-2896, 1989.

SÖDERQUIST, L.; JANSON, L.; LARSSON, K. et al. Sperm morphology and fertility in A.I. bulls. Journal of Veterinary Medicine, v.38, p.534-543, 1991.

SWERDLOFF, R.S.; WANG, C. Clinical evaluation of Leydig cell function. In: PAYNE, A.H.; HARDY, M.P.; RUSSELL, L.D. (Eds.) The Leydig cell. Vienna: Cache River, 1996. p.663-694.
THUNDATHIL, J.; PALASZ, A.D.; MAPLETOFT, R.J. et al. The use of in vitro fertilization techniques to investigate the fertilizing ability of bovine sperm with proximal cytoplasmatic droplets. Animal Reproduction Science, v.65, p.181-192, 2001.

TROCÓNIZ, J.F.; BELTRÁN, J.; BASTIDAS, H. et al. Testicular development, body weight changes, puberty and semen traits of growing Guzerat and Nellore bulls. Theriogenology, v.35, n.4, p.815-826, 1991.

UNANIAN, M.M. Uso de marcadores moleculares na busca de características relacionadas à produção animal. In: SIMPÓSIO DE RECURSOS GENÉTICOS PARA AMÉRICA LATINA E CARIBE-SIRGEALC, 2., 1999, Brasília. Anais... Brasília: EMBRAPA Recursos Genéticos e Biotecnologia, [1999] 8p. CD-ROM. Sessão Palestras.

UNANIAN, M.M. Integridade da cromatina: método complementar para avaliação da qualidade do sêmen bovino. Brasília: EMBRAPA Recursos Genéticos e Biotecnologia, 2000. 21p. (Embrapa Recursos Genéticos e Biotecnologia. Documentos, 56).

UNANIAN, M.M.; SILVA, A.E.D.F.; McMANUS, C. et al. Características biométricas testiculares para avaliação de touros zebuínos da raça Nelore. Revista Brasileira de Zootecnia, v.29, n.1, p.136-144, 2000.

VOGLER, C.J.; BAME, J.H.; DeJARNETTE, J.M. et al. Effects of elevated testicular temperature on morphology characteristics of ejaculated spermatozoa in the bovine. Theriogenology, v.40, p.1207-1219, 1993. 